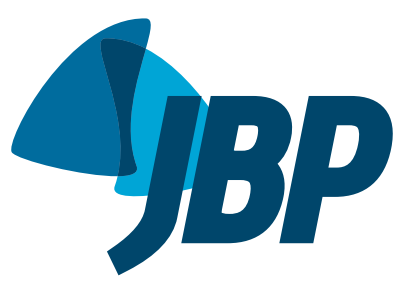

1. Serviço de Farmácia, Complexo Hospitalar Universitário Professor Edgard Santos, Universidade Federal da Bahia, Salvador (BA) Brasil.

2. Faculdade de Farmácia, Universidade Federal da Bahia, Salvador (BA) Brasil

Submitted: 5 January 2015 Accepted: 11 September 2015

Study carried out at the Programa de Controle da Asma na Bahia

Salvador (BA) Brasil.

\section{Factors associated with quality of life in patients with severe asthma: the impact of pharmacotherapy}

\author{
Daiane Silva Souza', Lúcia de Araújo Costa Beisl Noblat ${ }^{2}$, Pablo de Moura Santos ${ }^{1}$
}

\begin{abstract}
Objective: To identify, characterize, and quantify associations of various factors with quality of life (QoL) in patients with asthma, according to the pharmacotherapy employed. Methods: This was a cross-sectional study involving 49 patients ( $\geq 18$ years of age) with severe uncontrolled or refractory asthma treated at a specialized outpatient clinic of the Brazilian Unified Health Care System, regularly using high doses of inhaled corticosteroids (ICS) or other medications, and presenting comorbidities. At a single time point, QoL was assessed with the Asthma Quality of Life Questionnaire (AQLQ). The overall AQLQ score and those of its domains were correlated with demographic variables (gender and age); Asthma Control Questionnaire score; pharmacotherapy (initial IC dose, inhaler devices, and polytherapy); and comorbidities. Results: Better AQLO scores were associated with asthma control-overall $(\mathrm{OR}=0.38 ; 95 \% \mathrm{Cl}$ : $0.004-$ $0.341 ; p<0.001$ ), "symptoms" domain (OR $=0.086 ; 95 \% \mathrm{Cl}: 0.016-0.476 ; \mathrm{p}=0.001$ ), and "emotional function" domain (OR $=0.086 ; 95 \% \mathrm{Cl}: 0.016-0.476 ; \mathrm{p}=0.001)$-and with IC dose $\leq 800 \mu \mathrm{g}$ - "activity limitation" domain $\mathrm{OR}=0.249 ; 95 \% \mathrm{Cl}$ : 0.070-0.885; $\mathrm{p}=0.029$ ). Worse AQLQ scores were associated with polytherapy_ "activity limitation" domain (OR $=3.651 ; 95 \% \mathrm{Cl}: 1.061-12.561 ; \mathrm{p}=0.036$ ) -and number of comorbidities $\leq 5$ - "environmental stimuli" domain (OR $=5.042 ; 95 \% \mathrm{Cl}: 1.316-19.317 ; \mathrm{p}=0.015)$. Conclusions: Our results, the importance of this issue, and the lack of studies taking pharmacotherapy into consideration warrant longitudinal studies to establish a causal relationship between the identified factors and $\mathrm{QoL}$ in asthma patients.
\end{abstract}

Keywords: Asthma; Asthma/drug therapy; Quality of life; Medication therapy management.

\section{INTRODUCTION}

Asthma is a chronic inflammatory disease of the lower airways and is among the most common chronic conditions, affecting children and adults. It is characterized by increased airway responsiveness to a variety of stimuli, resulting in airflow obstruction that is typically recurrent and reversible. ${ }^{(1)}$

Asthma treatment and its duration play a role in the severity of the aforementioned clinical manifestations (i.e., the severity of asthma). The more severe the clinical manifestations of asthma, the greater the difficulty in managing the disease. ${ }^{(2)}$

The estimated prevalence of asthma in Brazil is $10 \%$. In large Brazilian cities, the mean prevalence of asthma symptoms is $24.3 \%$ in children and $19.0 \%$ in adolescents. A history of wheezing has been reported in $46.6 \%$ of the children living in the city of Salvador, Brazil, as has a trend toward an increase in the rate of physician-diagnosed asthma among children and adolescents in Brazil. ${ }^{(3,4)}$

In 2003, the Programa de Controle da Asma e da Rinite Alérgica na Bahia (ProAR, Bahia State Program for the Control of Asthma and Allergic Rhinitis) was created. The ProAR is a multidisciplinary education, research, and treatment program integrating the Sistema Único de Saúde (SUS, Brazilian Unified Health Care System) and the Federal University of Bahia, located in the city of Salvador. The ProAR focuses on preventing and treating asthma and allergic rhinitis; providing free medication regularly; reducing hospitalizations, emergency room visits, and mortality; and improving quality of life (QoL). ${ }^{(5-7)}$

The information obtained by assessing the QoL of patients treated at a given health care facility can inform decisions regarding the choice of procedures and treatments for achieving optimal patient health. ${ }^{(8)}$ According to La Scala et al., QoL assessment is relevant to clinical practice because treatment planning and progression are focused on the patient rather than on the disease. They also state that a holistic approach is required in order to assess QoL, which should not be seen purely in terms of treatment outcome. ${ }^{(9)}$

The Asthma Quality of Life Questionnaire (AQLQ) is a disease-specific instrument that was developed in 1992 specifically for use in clinical studies. It is the instrument that is most widely used in asthma studies. The AQLQ comprises domains assessing multiple aspects of the daily life of asthma patients and assesses their physical and emotional status, thus allowing assessment of the subjective experience of asthma. It was validated for use in Brazil in 2007. ${ }^{(10,11)}$ 
The use of inhaler devices in the pharmacotherapy of asthma requires patient education on inhaler technique and handling. Optimal inhaler use increases lung drug deposition and, consequently, treatment efficacy, resulting in asthma control, which is important for a better QoL. ${ }^{(12)}$ The level of patient satisfaction with their inhaler device has been found to have a positive influence on patient-reported outcomes in asthma, resulting in fewer emergency room visits, fewer nocturnal exacerbations, and improved QoL. ${ }^{(13)}$

Studies have shown a correlation between the level of asthma control and QoL. Questionnaires have been developed in order to assess the level of asthma control, and studies have assessed the correlation between asthma control and QoL. ${ }^{14,15)}$ The Asthma Control Questionnaire (ACQ) is an instrument that can be used in clinical practice, clinical trials, and cross-sectional studies, ACQ scores correlating well with AQLQ scores. ${ }^{(14,16)}$

Severe asthma has been associated with numerous comorbidities that are related to poor asthma control, increased use of the health care system, and reduced QoL, the management of which has been reported to have a positive impact on asthma outcomes. ${ }^{(17)}$ Comorbidities are common and include allergic rhinitis, obesity, osteoporosis, gastroesophageal reflux disease, tuberculosis, hypertension, and diabetes. ${ }^{(18)}$

In addition to presenting with comorbidities, asthma patients are often on polypharmacy. The risk of drug interactions and adverse drug reactions increases exponentially with the number of drugs used. Iatrogenic complications can lead to the addition of other medications, polypharmacy therefore being a public health problem that has a negative impact on patient QoL. ${ }^{(19)}$

In Bahia, patients with severe asthma have access to a program that provides treatment with inhaled corticosteroids (ICs) and bronchodilators, as well as asthma education and guidance on the use of inhalers. However, given the complexity of the pharmacological treatment of severe asthma and the clinical manifestations of the underlying disease, asthma management involves more than disease control and access to drugs. In the context of pharmaceutical care, few studies have examined the impact of pharmacotherapy on the QoL of patients with severe asthma.

Given the importance of this issue, the objective of the present study was to identify and characterize factors associated with QoL in patients with severe asthma treated at a referral center in the city of Salvador, as well as to determine the association of QoL-related factors with AQLQ scores (overall and individual domain scores).

\section{METHODS}

This was a cross-sectional study to assess the QoL of patients with severe asthma. The study was conducted between September and November of 2013. The data were collected from the database of a randomized controlled clinical trial conducted at an SUS asthma outpatient clinic, where the ProAR is headquartered.

The study population consisted of patients 18 years of age or older treated at the ProAR outpatient clinic and presenting with severe asthma, refractory asthma, or uncontrolled asthma (or meeting clinical criteria for severe asthma); receiving drugs regularly from the ProAR pharmacy; using polypharmacy, high-dose ICs, or both; presenting with comorbidities; and having an $\mathrm{FEV}_{1} \leq 60 \%$ of predicted.

At a single time point, QoL was assessed with the AQLQ, which was administered by three previously trained pharmacists. The AQLQ is a disease-specific questionnaire consisting of 32 items grouped into four domains: activity limitation (11 items); symptoms (12 items); emotional function (5 items); and environmental stimuli (4 items). It can be interviewer-administered or self-administered. The overall AQLQ score is the arithmetic mean of all items, the minimum score being 1 (extremely low QoL) and the maximum score being 7 (excellent QoL). ${ }^{(10)}$

The level of asthma control was assessed with the $A C Q$, which was administered at the same time point as was the AQLQ. The ACQ consists of seven questions: five questions regarding symptoms; one question regarding the use of short-acting $\beta_{2}$ agonists; and one question regarding $\mathrm{FEV}_{1}$. All items have the same weight, and the level of asthma control is given by the arithmetic mean of all items, ranging from zero (well-controlled asthma) to six (severely uncontrolled asthma). (20)

The following data were collected from the aforementioned database: sociodemographic data (gender, age level of education, race, and occupation); clinical data (history of smoking, history of pulmonary tuberculosis, presence of other respiratory diseases, diagnosis of refractory asthma, BMI, presence of comorbidities, percent predicted $\mathrm{FEV}_{1}$, and ACQ scores); clinical data on pharmacotherapy (starting dose of ICs, types of inhalers, number of inhalers, and number of drugs used); and QoL data (AQLQ scores).

Given that the AQLQ was administered at a single time point, a cut-off score of 4 (moderate QoL) was used as reference. Scores $>4$ were considered to indicate moderate-to-excellent QoL, whereas scores $\leq$ 4 were considered to indicate moderate-to-poor QoL. ${ }^{(21)}$

For the ACQ, the cut-off score was set at 1.5. Scores $\leq 1.5$ were considered to indicate controlled asthma, whereas scores $>1.5$ were considered to indicate uncontrolled asthma. ${ }^{(20)}$

Polytherapy was defined as the use of at least five drugs. ${ }^{(19)}$

High-dose IC use was defined as the use of more than $800 \mu \mathrm{g}$ of budesonide or equivalent. ${ }^{(2)}$

Descriptive statistics were calculated for sociodemographic, clinical, QoL, and pharmacotherapy variables.

The Kolmogorov-Smirnov test was used in order to determine whether quantitative variables were normally 
distributed. Variables with normal distribution were summarized as means, whereas those with non-normal distribution were summarized as medians.

For variables with normal distribution, the Student's t-test was used in order to assess significant differences between comparison groups. For variables with non-normal distribution, the Mann-Whitney test was used. The value of $p$ was derived from those two tests, in accordance with the characteristics of the study variables.

The variables of interest were dichotomized as follows: gender (male/female); age ( $<60$ years/ $\geq$ 60 years); number of inhalers used in combination ( $\leq 2$ inhalers/> 2 inhalers); IC dose $(\leq 800 \mu \mathrm{g} />800$ $\mu \mathrm{g})$; polytherapy (yes/no); level of asthma control $(\mathrm{ACQ} \leq 1.5 / \mathrm{ACQ}>1.5)$; number of comorbidities ( $\leq 5$ comorbidities/> 5 comorbidities); overall AQLQ score and individual AQLQ domain scores ( $\leq 4 />4)$. The odds ratios (ORs) for the associations of the study variables with the overall AQLQ score and those of its domains were thus estimated.

Finally, the factors associated with QoL in the study sample were identified and characterized, and their association with the overall AQLQ score and individual AQLQ domain scores was determined.

Independent variables were associated with better QoL when $0<\mathrm{OR}<1$, being associated with worse QoL when OR $>1$. An OR of 1 indicated that there was no association between a given independent variable and QoL. Values of $p<0.05$ were considered statistically significant.

The present study was approved by the Research Ethics Committee of the Federal University of Bahia Professor Edgard Santos University Hospital (CAAE $128 / 2008)$, in the city of Salvador.

Statistical analysis was performed with the Statistical Package for the Social Sciences, version 14.0 (SPSS Inc., Chicago, IL, USA).

\section{RESULTS}

Of the 50 patients whose data were available in our database, 49 (98\%) were evaluated in the present study, $1(2 \%)$ being excluded from the analysis because of missing data.

The sociodemographic and clinical characteristics of the patients studied are presented in Table 1 . The data on pharmacotherapy are presented in Table 2.

The AQLQ scores reveal a moderate QoL in our sample (approximately 4), both regarding the overall AQLQ scores and the AQLQ domain scores (Table 3).

Neither the overall AQLQ score nor individual AQLQ domain scores showed significant differences regarding gender, age, or number of inhalers used in combination. Although the overall AQLQ score did not show statistically significant differences regarding IC dose, polytherapy, or number of comorbidities, some of the individual AQLQ domain scores did.
There was a statistically significant difference between the level of asthma control (mean ACQ scores) and the overall AQLQ score ( $p<0.01)$.

Regarding the AQLQ domain scores, there were statistically significant differences of polytherapy and IC dose with AQLQ "activity limitation" domain scores.

There was a statistically significant difference between the number of comorbidities and AQLQ "environmental stimuli" domain scores.

Asthma control (ACQ scores) was found to show statistically significant differences with AQLQ "emotional function" and "symptoms" domain scores (Table 4).

The ORs for the associations of the study variables with the overall AQLQ score and those of its domains are shown in Table 4.

\section{DISCUSSION}

In the present study, neither the overall AQLQ score nor individual AQLQ domain scores were significantly associated with gender, age, or number of inhalers used in combination.

In contrast, the overall AQLQ score and those of its domains (symptoms, activity limitation, emotional function, and environmental stimuli) were significantly associated with the following variables: polytherapy; IC dose; ACQ score; and number of comorbidities.

Of the study variables, polytherapy and IC dose are directly related to the pharmacological treatment of asthma. In contrast, the ACQ score and the number of comorbidities are indirectly related to the pharmacological treatment of asthma.

The ACQ score is indirectly related to the pharmacological treatment of asthma because the latter is aimed at controlling the disease, reducing airway remodeling, and reducing mortality. ${ }^{(1,15)}$ The number of comorbidities is also related to the pharmacological treatment of asthma, in the form of polytherapy use or untreated conditions. Therefore, the association of those variables with QoL was assessed (with the AQLQ).

Many studies have assessed the QoL of asthma patients, showing that severe asthma has a strong impact on QoL. ${ }^{(9-11,22,23)}$

Given that the present study was a cross-sectional study in which the AQLQ was administered at a single time point, an AQLQ score of 4 (i.e., moderate QoL) was used as a cut-off point for the association of independent variables with QoL. In another cross-sectional study, the same cut-off point was used in order to assess the QoL of asthma patients at a single time point. The AQLQ is an instrument that is cross-sectionally and longitudinally correlated with clinical measures. ${ }^{(10,24)}$

The concept of polytherapy remains controversial in the literature. Studies have shown that polytherapy does not improve the QoL of patients, as well as showing drug interaction rates as high as $50 \%$ and the possibility of iatrogenic complications from the concomitant use of at least five drugs. (19,25-27) $^{2}$ 
Table 1. Sociodemographic and clinical characteristics of 49 patients with severe or refractory asthma treated at a Brazilian Unified Health Care System asthma outpatient clinic in the city Salvador, Brazil.a

\begin{tabular}{|c|c|}
\hline Characteristic & Result \\
\hline Age, years & $53.6 \pm 13.4$ \\
\hline \multicolumn{2}{|l|}{ Gender } \\
\hline Female & $41(84)$ \\
\hline Male & $8(16)$ \\
\hline \multicolumn{2}{|l|}{ Race } \\
\hline Black & $22(45)$ \\
\hline Mulatto & $7(14)$ \\
\hline White & $7(14)$ \\
\hline Other & $6(13)$ \\
\hline No data & $7(14)$ \\
\hline \multicolumn{2}{|l|}{ Occupation } \\
\hline Homemaker & $18(37)$ \\
\hline $\begin{array}{l}\text { Workers in the } \\
\text { commercial sector }\end{array}$ & $3(6)$ \\
\hline Legal assistant & $7(14)$ \\
\hline Retired & $10(20)$ \\
\hline Seamstress & $2(4)$ \\
\hline Housekeeper & $2(4)$ \\
\hline Unemployed & $1(2)$ \\
\hline Other & $6(14)$ \\
\hline \multicolumn{2}{|l|}{ Level of education } \\
\hline Illiterate & $2(4)$ \\
\hline 9 years of schooling & $28(57)$ \\
\hline High school & $12(25)$ \\
\hline College & $7(14)$ \\
\hline \multicolumn{2}{|l|}{ History of smoking } \\
\hline Yes & $19(38)$ \\
\hline No & $30(62)$ \\
\hline \multicolumn{2}{|c|}{ History of pulmonary tuberculosis } \\
\hline Yes & $12(25)$ \\
\hline No & $37(76)$ \\
\hline \multicolumn{2}{|l|}{ Refractory asthma } \\
\hline Yes & $10(20)$ \\
\hline No & $39(80)$ \\
\hline \multicolumn{2}{|l|}{ Obesity } \\
\hline Yes & $14(29)$ \\
\hline No & $35(71)$ \\
\hline $\mathrm{FEV}_{1}, \%$ of predicted & $47.6 \pm 15.8$ \\
\hline
\end{tabular}

avalues expressed as $\mathrm{n}(\%)$. or as mean \pm SD.

In the present study, polytherapy was significantly associated with AQLQ "activity limitation" domain scores. It can be assumed that the use of polytherapy increased the likelihood of worse QoL outcomes in the "activity limitation" domain. Although mean overall scores were more likely to be negatively influenced by the "activity limitation" domain score $(<4$, i.e., moderate-to-poor QoL), there was no significant association between polypharmacy and the overall AQLQ score to confirm this assumption.

The level of asthma control (as measured by the ACQ) was found to be a "protective factor" for the overall AQLQ score and for AQLQ "symptoms" and
Table 2. Descriptive statistics for the independent variables associated with pharmacotherapy in patients with severe asthma treated at an asthma referral center in the city of Salvador, Brazil.a

\begin{tabular}{|c|c|}
\hline Variable & Result \\
\hline ACQ score ${ }^{b}$ & $2.73 \pm 1.37$ \\
\hline Number of comorbidities ${ }^{c}$ & $4(2-8)$ \\
\hline Inhaled corticosteroid dose, $\mu \mathrm{g}^{\mathrm{c}}$ & $1,600(800-1,800)$ \\
\hline $\begin{array}{l}\text { Combined use of inhaler } \\
\text { devices (DPI + MDI) }\end{array}$ & $19(39)$ \\
\hline $\begin{array}{l}\text { Aerolizer }{ }^{\oplus} \text { used as the primary } \\
\text { treatment for asthma }\end{array}$ & $28(57)$ \\
\hline MDI used as an add-on device & $30(61)$ \\
\hline Concomitant use of at least 5 drugs & $31(62)$ \\
\hline
\end{tabular}

ACQ: Asthma Control Questionnaire; DPI: dry powder inhaler; and MDI: metered dose inhaler. aValues expressed as $\mathrm{n}(\%)$, except where otherwise indicated. bValue expressed as mean \pm SD. cValues expressed as median (range).

Table 3. Overall Asthma Quality of Life Questionnaire score and individual domain scores. ${ }^{a}$

\begin{tabular}{lc}
\multicolumn{1}{c}{ AQLQ score } & Result \\
Overall & $3.66 \pm 1.41$ \\
Symptoms domain & $3.69 \pm 1.52$ \\
Activity limitation domain & $3.59 \pm 1.45$ \\
Emotional function domain & $3.60 \pm 1.87$ \\
Environmental stimuli domain & $4(1-7)$ \\
\hline
\end{tabular}

AQLQ: Asthma Quality of Life Questionnaire. ${ }^{\text {aValues }}$ expressed as mean \pm SD or as median (range).

"emotional function" domain scores. An ACQ score $\leq 1.5$ (controlled asthma) increased the likelihood of better overall AQLQ scores ( $>4$ ) and better AQLQ "symptoms" and "emotional function" domain scores. Other studies have shown an association between well-controlled asthma and better QoL, patients with well-controlled asthma having higher overall AQLQ scores. ${ }^{(16,28)}$

In the present study, an association was found between the number of comorbidities and AQLQ "environmental stimuli" domain scores. It is of note that patients with fewer than five comorbidities were more likely to have worse "environmental stimuli" domain scores. Consequently, their overall AQLQ scores were more likely to be negatively influenced by their "environmental stimuli" domain scores, although the association was not statistically significant.

Although the study design does not allow causal interpretations, it is possible that, in our sample, there were patients with other respiratory diseases or with medical conditions influenced by factors associated with environmental stimuli, and that those factors played a role in the lack of asthma control (atopy, difficult-to-control allergic rhinitis, etc.). Therefore, it is possible that patient perception of QoL was negatively influenced by the presence of such comorbidities, regardless of the number of comorbidities.

Allergy might be linked to asthma by genetic or environmental factors. ${ }^{(17)}$ However, allergy was not assessed in the present study. 
Table 4. Association of independent variables with the overall Asthma Quality of Life Questionnaire score and those of its individual domains.

\begin{tabular}{|c|c|c|c|c|c|c|c|c|c|c|}
\hline \multirow[t]{2}{*}{ Variable } & \multicolumn{2}{|c|}{ Overall score } & \multicolumn{2}{|c|}{$\begin{array}{l}\text { Symptoms } \\
\text { domain score }\end{array}$} & \multicolumn{2}{|c|}{$\begin{array}{l}\text { Activity limitation } \\
\text { domain score }\end{array}$} & \multicolumn{2}{|c|}{$\begin{array}{l}\text { Emotional function } \\
\text { domain score }\end{array}$} & \multicolumn{2}{|c|}{$\begin{array}{l}\text { Environmental stimul } \\
\text { domain score }\end{array}$} \\
\hline & $\begin{array}{c}\text { OR } \\
(95 \% \mathrm{CI})\end{array}$ & $\mathbf{p}$ & $\begin{array}{c}\text { OR } \\
(95 \% \mathrm{Cl})\end{array}$ & p & $\begin{array}{c}\text { OR } \\
(95 \% \mathrm{CI})\end{array}$ & p & $\begin{array}{c}\text { OR } \\
(95 \% \mathrm{CI})\end{array}$ & p & $\begin{array}{c}\text { OR } \\
(95 \% \mathrm{CI})\end{array}$ & p \\
\hline Gender & $\begin{array}{c}2.215 \\
(0.382- \\
11.828)\end{array}$ & 0.382 & $\begin{array}{c}0.962 \\
(0.201- \\
4.604)\end{array}$ & 0.961 & $\begin{array}{c}4.480 \\
(0.503- \\
39.919)\end{array}$ & 0.149 & $\begin{array}{c}1.920 \\
(0.344- \\
10.711)\end{array}$ & 0.452 & $\begin{array}{c}0.864 \\
(0.190- \\
3.932)\end{array}$ & 0.851 \\
\hline Age & $\begin{array}{c}1.064 \\
(0.467- \\
5.512)\end{array}$ & 0.451 & $\begin{array}{c}1.830 \\
(0.528- \\
6.342)\end{array}$ & 0.338 & $\begin{array}{c}2.100 \\
(0.599- \\
7.361)\end{array}$ & 0.242 & $\begin{array}{c}0.808 \\
(0.225- \\
2.896)\end{array}$ & 0.743 & $\begin{array}{c}3.231 \\
(0.901- \\
11.586)\end{array}$ & 0.069 \\
\hline $\begin{array}{l}\text { Number of } \\
\text { inhalers }\end{array}$ & $\begin{array}{c}0.900 \\
(0.285- \\
2.843)\end{array}$ & 0.858 & $\begin{array}{c}0.750 \\
(0.234- \\
2.408)\end{array}$ & 0.628 & $\begin{array}{c}0.889 \\
(0.274- \\
2.885)\end{array}$ & 0.845 & $\begin{array}{c}1.067 \\
(0.334-3.40)\end{array}$ & 0.913 & $\begin{array}{c}2.489 \\
(0.787- \\
7.870)\end{array}$ & 0.121 \\
\hline Polytherapy & $\begin{array}{c}1.800 \\
(0.554- \\
5.845)\end{array}$ & 0.326 & $\begin{array}{c}2.100 \\
(0.638- \\
6.916)\end{array}$ & 0.219 & $\begin{array}{c}3.651 \\
(1.061- \\
12.561)\end{array}$ & 0.036 & $\begin{array}{c}1.008 \\
(0.306- \\
3.318)\end{array}$ & 0.990 & $\begin{array}{c}1.029 \\
(0.325- \\
3.253)\end{array}$ & 0.962 \\
\hline ACQ score & $\begin{array}{c}0.380 \\
(0.004- \\
0.341)\end{array}$ & 0.000 & $\begin{array}{c}0.086 \\
(0.016- \\
0.476)\end{array}$ & 0.001 & $\begin{array}{c}0.262 \\
(0.062- \\
1.111)\end{array}$ & 0.060 & $\begin{array}{c}0.086 \\
(0.016- \\
0.476)\end{array}$ & 0.001 & $\begin{array}{c}0.298 \\
(0.067- \\
1.330)\end{array}$ & 0.105 \\
\hline $\begin{array}{l}\text { Number of } \\
\text { comorbidities }\end{array}$ & $\begin{array}{c}0.461 \\
(0.122- \\
1.741)\end{array}$ & 0.253 & $\begin{array}{c}0.317 \\
(0.075- \\
1.330)\end{array}$ & 0.110 & $\begin{array}{c}0.587 \\
(0.154- \\
2.237)\end{array}$ & 0.438 & $\begin{array}{c}0.808 \\
(0.225- \\
2.896)\end{array}$ & 0.745 & $\begin{array}{c}5.042 \\
(1.316- \\
19.317)\end{array}$ & 0.015 \\
\hline IC dose & $\begin{array}{c}0.500 \\
(0.148- \\
1.691)\end{array}$ & 0.266 & $\begin{array}{c}0.435 \\
(0.127- \\
1.487)\end{array}$ & 0.184 & $\begin{array}{c}0.249 \\
(0.070- \\
0.885)\end{array}$ & 0.029 & $\begin{array}{c}0.643 \\
(0.189- \\
2.187)\end{array}$ & 0.483 & $\begin{array}{c}1.771 \\
(0.522- \\
6.003)\end{array}$ & 0.362 \\
\hline
\end{tabular}

ACQ: Asthma Control Questionnaire; and IC: inhaled corticosteroid.

The results of the present study differ from those of other studies. According to Heyworth et al., a higher number of chronic conditions translates to a greater negative impact on QoL. ${ }^{(29)}$

The use of $\leq 800 \mu \mathrm{g}$ of budesonide or equivalent was found to be associated with better QoL outcomes in the "activity limitation" domain (a score > 4, i.e., moderate-to-excellent QoL) in the present study. Patients using $\leq 800 \mu \mathrm{g}$ of budesonide or equivalent were more likely to have better AQLQ "activity limitation" domain scores. Therefore, it is possible that the use of $\leq 800 \mu \mathrm{g}$ of budesonide or equivalent contributed positively to the overall AQLQ score. However, no statistically significant association was found between the use of $\leq 800 \mu \mathrm{g}$ of budesonide or equivalent and the overall AQLQ score to confirm this assumption.

The results of the present study differ from those of a study of patients with moderate to severe asthma before and after treatment with high-dose fluticasone (equivalent to $1,600 \mu \mathrm{g}$ of budesonide). ${ }^{(30)}$ The overall AQLQ score was correlated with better QoL, as were individual AQLQ domain scores. However, the aforementioned study was a longitudinal study of 60 patients. Therefore, it is possible that the degree of association in that study was different from that in the present study. In addition, the aforementioned study was not conducted in Brazil, meaning that various patient-related factors might have influenced QoL outcomes. ${ }^{(30)}$

In the present study, it was impossible to assess other aspects of pharmacotherapy, such as adherence to treatment, adverse reactions to ICs or other drugs, use of medicinal plants/herbal medicines, and stratification by drug class, because the available data were insufficient to do so.

Studies that have a cross-sectional design preclude the establishment of causal relationships between QoL and independent variables. However, the importance of this issue, the results presented herein, and the lack of QoL studies taking pharmacotherapy into consideration warrant longitudinal studies to establish such relationships.

The importance of this issue and the results of the present study indicate the need for studies investigating pharmacotherapy-related factors influencing the QoL of patients with severe asthma treated at an SUS referral outpatient clinic.

With regard to the goals established by the clinical protocols and treatment guidelines for asthma control, improving the QoL of patients with severe asthma is as important as choosing the appropriate pharmaceutical interventions and drug therapies, given that QoL reflects how patients perceive asthma management outcomes and how they live with the disease.

Pharmacists play an extremely important role in the management of severe asthma, recognizing pharmacotherapy-related factors associated with QoL measures and aiding in choosing the appropriate drug therapy for controlling asthma, reducing morbidity, reducing mortality, and enhancing patient well-being.

\section{ACKNOWLEDGMENTS}

We would like to thank all of those who contributed directly or indirectly to this work, in particular Aline 
Lima, Viviane Ferreira, Sóstenes Mistro, our colleagues in the Professor Edgard Santos University Hospital
Department of Pharmacy, the ProAR team, Carolina Vidal, and Elaine Almeida.

\section{REFERENCES}

1. Global Initiative for Asthma - GINA. [homepage on the Internet] Bethesda: Global Initiative for Asthma. [cited 2012 Oct 5]. Global Strategy for Asthma Management and Prevention. Available from: http://www.ginasthma.org

2. Cruz AA, Fernandes AL, Pizzichini E, Fiterman J, Pereira LF, Pizzichini M, et al. Diretrizes da Sociedade Brasileira de Pneumologia e Tisiologia Para o Manejo da Asma--2012. J Bras Pneumol. 2012;38(Suppl 1):S1-S46.

3. Solé D, Wandalsen GF, Camelo-Nunes IC, Naspitz CK; ISAAC Brazilian Group. Prevalence of symptoms of asthma, rhinitis, and atopic eczema among Brazilian children and adolescents identified by the International Study of Asthma and Allergies in Childhood (ISAAC) - Phase 3. J Pediatr (Rio J). 2006;82(5):341-6. http://dx.doi. org/10.1590/S0021-75572006000600006

4. Solé D, Melo KC, Camelo-Nunes IC, Freitas LS, Britto M, Rosário $N A$, et al. Changes in the prevalence of asthma and allergic diseases among Brazilian schoolchildren (13-14 years old): comparison between ISAAC phases One and Three. J Trop Pediatr. 2007;53(1):13-21. http://dx.doi.org/10.1093/tropej/fml044

5. Ponte E, Souza-Machado A, Franco RA, Sarkis V, Shah K, SouzaMachado $C$ et al. Asthma and allergic rhinitis control program for state of Bahia (ProAr): a model for integration of health care, teaching and research [Article in Portuguese]. Rev Baiana Saude Publica. 2004;28(1):124-32.

6. Ponte EV, Souza-Machado A, Souza-Machado C, Franco R, Cruz AA. Clinical characteristics and prognosis in near-fatal asthma patients in Salvador, Brazil. J Bras Pneumol. 2011;37(4):431-7. http://dx.doi. org/10.1590/S1806-37132011000400004

7. Ponte E, Franco RA, Souza-Machado A, Souza-Machado C, Cruz AA. Impact that a program to control severe asthma has on the use of Unified Health System resources in Brazil. J Bras Pneumol. 2007;33(1):15-9. http://dx.doi.org/10.1590/S180637132007000100006

8. Seidl EM, Zannon CM. Quality of life and health: conceptual and methodological issues [Article in Portuguese]. Cad Saude Publica. $\quad 2004 ; 20(2): 580-8 . \quad$ http://dx.doi.org/10.1590/S0102$311 \times 2004000200027$

9. La Scala CS, Naspitz CK, Solé D. Quality of life in asthma: How to evaluate it? [Article in Portuguese]. Rev Bras Alerg Imunopatol. 2004;27(6):217-30.

10. Juniper EF, Buist AS, Cox FM, Ferrie PJ, King DR. Validation of a standardized version of the Asthma Quality of Life Questionnaire. Chest. 1999;115(5):1265-70. http://dx.doi.org/10.1378/ chest.115.5.1265

11. Silva LM, Silva LL. Validação do questionário de qualidade de vida em asma (Juniper) para o português brasileiro. Rev AMRGS. 2007:51(1):31-7

12. Mastalerz L, Kasperkiewicz H. Effect of inhaled corticosteroids on small airway inflammation in patients with bronchial asthma. Pol Arch Med Wewn. 2011;121(7-8):264-9.

13. Small M, Anderson $P$, Vickers A, Kay $S$, Fermer S. Importance of inhaler-device satisfaction in asthma treatment: real-world observations of physician-observed compliance and clinical/patientreported outcomes. Adv Ther. 2011;28(3):202-12. http://dx.doi. org/10.1007/s12325-010-0108-4

14. Juniper EF, Wisniewski ME, Cox FM, Emmett AH, Nielsen KE, O'Byrnez PM. Relationship between quality of life and clinical status in asthma: a factor analysis. Eur Respir J. 2004;23(2):287-91. http:// dx.doi.org/10.1183/09031936.04.00064204

15. Pereira ED, Cavalcante AG, Pereira EN, Lucas P, Holanda MA Asthma control and quality of life in patients with moderate or severe asthma. J Bras Pneumol. 2011;37(6):705-11.

16. Juniper EF, O'Byrne PM, Guyatt GH, Ferrie PJ, King DR Development and validation of a questionnaire to measure asthma control. Eur Respir J. 1999;14(4):902-7. http://dx.doi.org/10.1034/ j.1399-3003.1999.14d29.x

17. Gershon AS, Guan J, Wang C, Victor JC, To T. Describing and quantifying asthma comorbidity [corrected]: a population study. PLoS One. 2013;7(5):e34967. http://dx.doi.org/10.1371/journal. pone.0034967

18. Cazzola M, Calzetta L, Bettoncelli G, Novelli L, Cricelli C, Roglian P. Asthma and comorbid medical illness. Eur Respir J. 2011;38(1):42-9. http://dx.doi.org/10.1183/09031936.00140310

19. Diniz JS, Ferreira F, Medeiros-Souza P, Santos-Neto LL, Silveira AN Lowande TS. Medicamentos em idosos. In: Brasil. Ministério da Saúde. Formulário Terapêutico Nacional 2010--Rename 2010. 2nd ed. Brasília: Ministério da Saúde; 2010. p. 41-4

20. Juniper EF, Bousquet J, Abetz L, Bateman ED; GOAL Committee. Identifying 'well-controlled' and 'not well-controlled' asthma using the Asthma Control Questionnaire. Respir Med. 2006;100(4):616-21. http://dx.doi.org/10.1016/j.rmed.2005.08.012

21. Ferreira LN, Brito U, Ferreira PL. Quality of life in asthma patients. Rev Port Pneumol. 2010;16(1):23-55. http://dx.doi.org/10.1016/ S0873-2159(15)30005-2

22. Guyatt GH, Juniper EF, Walter SD, Griffith LE, Goldstein RS Interpreting treatment effects in randomized trials. BMJ. 1998;316(7132):690-3. http://dx.doi.org/10.1136/bmj.316.7132.690

23. Lavoie KL, Bacon SL, Barone S, Cartier A, Ditto B, Labrecque M. What is worse for asthma control and quality of life: depressive disorders, anxiety disorders, or both? Chest. 2006;130(4):1039-47. http://dx.doi.org/10.1378/chest.130.4.1039

24. Juniper EF, Guyatt GH, Ferrie PJ, Griffith LE. Measuring quality of life in asthma. Am Rev Respir Dis. 1993;147(4):832-8. http://dx.doi. org/10.1164/ajrccm/147.4.832

25. Delafuente JC. Understanding and preventing drug interactions in elderly patients. Crit Rev Oncol Hematol. 2003;48(2):133-43. http:// dx.doi.org/10.1016/j.critrevonc.2003.04.004

26. Carvalho MF, Romano-Lieber NS, Bergsten-Mendes G, Secoli $\mathrm{SR}$, Ribeiro $\mathrm{E}$, Lebrão $\mathrm{ML}$, et al. Polypharmacy among the elderly in the city of São Paulo, Brazil - SABE Study. Rev Bras Epidemiol. 2012;15(4):817-27. http://dx.doi.org/10.1590/S1415790X2012000400013

27. Maggiore RJ, Gross CP, Hurria A. Polypharmacy in older adults with cancer. Oncologist. 2010;15(5):507-22. http://dx.doi.org/10.1634/ theoncologist.2009-0290

28. Bateman ED, Frith LF, Braunstein GL. Achieving guidelinebased asthma control: does the patient benefit? Eur Respir J. 2002;20(3):588-95. http://dx.doi.org/10.1183/09031936.02.0029470 2

29. Heyworth IT, Hazell ML, Linehan MF, Frank TL. How do common chronic conditions affect health-related quality of life? Br J Gen Pract. 2009;59(568):e353-8. http://dx.doi.org/10.3399/bjgp09X453990

30. Choi JS, Jang AS, Lee JH, Park JS, Park SW, Kim DJ, et al. Effect of high dose inhaled glucocorticoids on quality of life in patients with moderate to severe asthma. J Korean Med Sci. 2005;20(4):586-90. http://dx.doi.org/10.3346/jkms.2005.20.4.586

\section{ERRATUM}

Manuscript: Factors associated with quality of life in patients with severe asthma: the impact of pharmacotherapy.

Publication: J Bras Pneumol. 2015;41(6):496-501. 
Factors associated with quality of life in patients with severe asthma: the impact of pharmacotherapy

DOI: http://dx.doi.org/10.1590/S1806-37562015000004545

On page 496 of the original publication, abstract, Results, line 12 , where it is written

"Better AQLQ scores were associated with asthma control-overall (OR = 0.38; 95\% CI: 0.004-0.341; p < 0.001)"

it should read

"Better AQLQ scores were associated with asthma control-overall ( $\mathrm{OR}=0.038 ; 95 \% \mathrm{CI}: 0.004-0.341 ; \mathrm{p}<$ $0.001)^{\prime \prime}$

On page 500 of the original publication, Table 4, second column, fifth row, where it is written

"0.380 (0.004-0.341)"

it should read

"0.038 (0.004-0.341)" 